\title{
Remodeling and angiotensin II responses of the uterine arcuate arteries of pregnant rats are altered by low- and high-sodium intake
}

\author{
Jean St-Louis, Benoît Sicotte, Annie Beauséjour and Michèle Brochu \\ Laboratoire de Recherche Fondamentale en Obstétrique, Centre de Recherche, Département d'Obstétrique et \\ Gynécologie, Hôpital Sainte-Justine, Université de Montréal, 175 Ch. Côte Sainte-Catherine, Montréal, \\ Québec H3T 1C5, Canada
}

Correspondence should be addressed to J St-Louis; Email: jean.st-louis@umontreal.ca

\begin{abstract}
Lowering and increasing sodium intake in pregnant rats evoke opposite changes in renin-angiotensin-aldosterone system (RAAS) activity and are associated with alterations of blood volume expansion. As augmented uterine blood flow during gestation is linked to increased circulatory volume, we wanted to determine if low- and high-sodium intakes affect the mechanical properties and angiotensin II (AngII) responses of the uterine vasculature. Non-pregnant and pregnant rats received a normal sodium $\left(0.22 \% \mathrm{Na}^{+}\right)$diet. On the 15 th day of gestation some animals were moved to a low-sodium $(0.03 \%)$ diet, whereas others were given $\mathrm{NaCl}$ supplementation as beverage (saline, $0.9 \%$ or $1.8 \%$ ) for 7 days. All rats were killed after 7 days of treatment (eve of parturition). Uterine arcuate arteries $(>\mathbf{1 0 0} \mu \mathrm{m})$ were set up in wire myographs under a tension equivalent to $50 \mathrm{mmHg}$ transmural pressure. The pregnancy-associated increase in diameter of the uterine arteries was significantly attenuated on the low-sodium diet and $1.8 \% \mathrm{NaCl}$ supplementation. The arcuate arteries of non-pregnant rats on the low-sodium diet showed markedly increased responses to AngII and phenylephrine (Phe). Pregnancy also resulted in heightened responses to AngII and Phe that were significantly reduced for the former agent in rats on the low-sodium diet. Sodium supplementation of non-pregnant rats did not affect the reactivity of the uterine arteries to Angll, but significantly reduced the effect of Phe ( $1 \mu \mathrm{mol} / \mathrm{l})$. High salt also significantly diminished the elevated responses to Angll in the arteries of pregnant animals. It was observed that altered sodium intake affects the mechanical and reactive properties of the uterine arcuate arteries more importantly in pregnant than in non-pregnant rats. Low-salt intake similarly affected the reactivity of the uterine arcuate arteries to AngII and Phe, whereas high-salt intake more specifically affected AngII responses. These results showed that perturbations of sodium intake have major impacts on the structure and functions of the uterine arterial circulation, indicating RAAS involvement in uterine vascular remodeling and function during gestation.

Reproduction (2006) 131 331-339
\end{abstract}

\section{Introduction}

Plasma renin activity (PRA) is elevated during pregnancy in association with increased cardiac output and plasma volume and with reduced blood pressure and peripheral resistance. In pre-eclampsia, PRA is comparatively decreased and, sometimes, in more severe cases, is below the levels in non-pregnant women (Baylis et al. 1998). This occurs simultaneously with blood pressure elevation and reduction of plasma volume expansion. The paradoxical relationship between PRA and blood pressure has been further documented recently. For instance, pregnant rats on a low-sodium diet $(0.03 \%)$ for the 3 rd week of gestation still manifested decreased blood pressure before parturition, whereas PRA and plasma aldosterone concentrations were markedly augmented (Roy-Clavel et al. 1999). In contrast, increased sodium intake during the same period prevented the reduction of blood pressure while markedly depressing PRA and plasma aldosterone (Beauséjour et al. 2003). Excessive dietary sodium has been linked to the development of hypertension (Simon \& Illyes 2001). It has also been well documented that sodium depletion (furosemide plus a sodium-free diet and distilled water as beverage) induces down-regulation of total angiotensin II (AngII) receptors and up-regulation of vasopressin receptors in the mesenteric vasculature of male rats (St-Louis \& Schiffrin 1984). Modification of sodium intake is, then, a readily available procedure to study the influence of the renin-angiotensin-aldosterone system (RAAS). 
During pregnancy, the uterine circulation is subjected to substantial structural and functional changes to meet the growing needs of the fetus(es). These phenomena have been reviewed with special emphasis on pregnant sheep (Rosenfeld 2001). Several studies have shown that the uterine blood vessels enlarge in size via both hypertrophic and hyperplastic mechanisms (Osol \& Cipolla 1993a, Cipolla \& Osol 1994, Cipolla et al. 2000) and that a major part of these changes takes place during the last week of gestation in rats (St-Louis et al. 1997). Moreover, these important structural alterations are accompanied by functional modulations of vascular reactivity (Osol \& Cipolla 1993b, D’Angelo \& Osol 1994, Ni et al. 1997, St-Louis et al. 1997, 2001, Zwart et al. 1998). For instance, the uterine arterial effects of vasoconstrictor agonists like Angll and $\alpha$-adrenomimetics, acting on $G$ protein-coupled receptors, are much stronger at term pregnancy ( $\mathrm{D}^{\prime}$ Angelo \& Osol 1994, St-Louis et al. 1997). We have reported that losartan, an AngIl (AT ${ }_{1}$-type) receptor blocker, has much weaker effects in the uterine arteries of term pregnant and early post-partum compared with non-pregnant rats (St-Louis et al. 2001). This result indicates that pregnancy is associated with significant regulation of Angll receptor subtypes $\left(\mathrm{AT}_{1} / \mathrm{AT}_{2}\right)$ relative to each other. Studies in sheep have revealed predominant binding of Angll to the $\mathrm{AT}_{2}$ receptor subtype in uterine artery smooth muscle (Cox et al. 1996a,b, Burrell \& Lumbers 1997). Moreover, it has been reported that $\mathrm{AT}_{1}$ receptor subtype expression is heightened in the uterine artery endothelium of pregnant sheep (Bird et al. 1997). Such data are not available for rats, presumably because of the very low expression of Angll receptors in the uterine vasculature of this species.

In the present study, we modified salt intake during gestation to investigate the impact of RAAS modulation on the structural and functional characteristics of uterine arcuate arteries in rats. Indeed, sodium restriction has been found to obliterate the increase of blood volume in normal gestation (Roy-Clavel et al. 1999). As heightened circulatory volume is required to augment uterine perfusion during gestation, it was suspected that any perturbation of the former should have a strong impact on both the remodeling and the function of the uterine vasculature. We hypothesized that increased and decreased RAAS activation during gestation, through reciprocal alterations of sodium intake, will modify remodeling and myotropic responses of the uterine arterial system associated with pregnancy.

\section{Materials and Methods}

\section{Animals}

Female Sprague-Dawley rats (10-11 weeks of age) obtained from Charles River Canada (St-Constant, QC, Canada) were mated with fertile males. Pregnant rats, and corresponding non-pregnant controls, were fed normal chow $(0.23 \%$ sodium; Teklad no. 2018; Harlan, Indianapolis, IN, USA) plus tap water for the first 15 days of gestation. Two groups of pregnant $(n=22)$ and non-pregnant $(n=24)$ rats were left on this regime for 7 more days. Two other groups of rats, ten non-pregnant and ten pregnant, were given a low-sodium diet $(0.03 \%$ sodium; no. 5881; PMI Feed Inc, Oakville, ON, Canada) plus demineralized water from days 15 to 22 of experimentation, corresponding to the 22nd day of gestation or the eve of parturition. Two additional groups of rats on normal chow, 13 non-pregnant and 13 pregnant, were given $0.9 \%$ saline to drink, while 12 non-pregnant and 17 pregnant rats received $1.8 \%$ saline for the last 7 days. A final group $(n=9)$ of pregnant rats was treated with polyethylene glycol (PEG, $15 \mathrm{ml} / \mathrm{kg}$ ) subcutaneously on days 15 , 18 and 21 of gestation to modify blood volume, with a corresponding pregnant control group $(n=7)$ being given an equivalent volume of saline. From day 7 of pregnancy until they were killed, systolic blood pressure, food and beverage intake, and weight were measured daily. These data for the groups on low- and high-sodium intakes are reported elsewhere (Roy-Clavel et al. 1999, Beauséjour et al. 2003). The PEG treatment group and its controls were added to the study because pregnant rats on lowsodium intake experience a significant decrease in blood volume. In these latter two groups, PRA and plasma aldosterone concentration were measured by RIA as in previous investigations (cited above), whereas hematocrit was quantified from an aliquot of blood collected for hormone analysis. All animals were guillotined at the end of treatment (22nd day of gestation) to harvest the uterine vasculature. The protocol was approved by the local animal care committee accredited by the Canadian Council for Animal Care.

\section{Myotropic responses of the uterine arcuate arteries}

The uterine horn and attached vasculature were rapidly removed and placed in cold oxygenated Krebs bicarbonate solution (KBS). An arcuate artery, at the midpoint of the uterine arcade, was cleaned of adhering tissues under a stereomicroscope. A section of about $1.5 \mathrm{~mm}$ was isolated, and two tungsten wires $(20 \mu \mathrm{m}$ diameter $)$ were inserted into the lumen to secure the vessel to myograph supports (Kent Scientific, Litchfield, CT, USA) (St-Louis et al. 1997, 2001). One support was attached to a strain gauge force transducer (TRN 001; Kent Scientific) and the other to a micrometer. Force was recorded on a computer with the Workbench data acquisition package (Kent Scientific). The arcuate artery segment was bathed in $7 \mathrm{ml}$ circulating KBS (in mmol/l: $\mathrm{NaCl}, 118 ; \mathrm{KCl}, 4.65 ; \mathrm{NaHCO}_{3}$, 25; $\mathrm{CaCl}_{2}, 2.5 ; \mathrm{MgSO}_{4}, 1.18 ; \mathrm{KH}_{2} \mathrm{PO}_{4}, 1.18$; and dextrose, 5.5), and bubbled with $95 \% \mathrm{O}_{2}$ and $5 \% \mathrm{CO}_{2} ; \mathrm{pH}$ was 7.4. A passive length-tension relationship was generated by increasing the distance (in steps of $25 \mu \mathrm{m}$ ) between the myograph supports. The results were fitted (Prism; GraphPad, San Diego, CA, USA) to an exponential equation that intercepted the theoretical straight line of Laplace (for a pressure of $50 \mathrm{mmHg}$ ) at diameter $\mathrm{L}_{50}\left(\mathrm{~L}_{50}\right.$; 
the diameter or internal circumference that the arterial segment would have at a transmural pressure of $50 \mathrm{~mm} \mathrm{Hg}$ ) used as passive tension (Mulvany \& Halpern 1977, St-Louis et al. 1997, 2001). After equilibration (30 min) at this tension, the vessels were challenged with $10^{-6} \mathrm{~mol} / \mathrm{l}$ phenylephrine (Phe) and, on top of this response, with $10^{-4} \mathrm{~mol} / \mathrm{l}$ carbachol to verify the presence of a functional endothelium. The rest of the experiment was performed with $10^{-4} \mathrm{~mol} / \mathrm{l} \mathrm{N}^{\omega}$-nitro-L-arginine methyl ester (L-NAME).

After returning to baseline, two cumulative concentration-response curves to Angll $\left(10^{-11}\right.$ to $\left.10^{-6} \mathrm{~mol} / \mathrm{l}\right)$ were obtained, first under basal conditions and then after 90-min re-equilibration, under $\mathrm{AT}_{1}$ receptor blockade with losartan $\left(10^{-7} \mathrm{~mol} / \mathrm{l}, 10-\mathrm{min}\right.$ preincubation). This protocol was not associated with tachyphylaxis to the pressor peptide (St-Louis et al. 2001).

\section{Data analysis}

Concentration-response curves were analysed by computer fitting to a four-parameter logistic equation (Prism) to evaluate the the Angll concentration required to produce $50 \%$ of the maximum response $\left(\mathrm{EC}_{50}\right)$ and the maximum response $\left(\mathrm{E}_{\mathrm{Max}}\right)$. The potency of the $\mathrm{AT}_{1}$ receptor antagonist losartan was measured by the method of Furchgott (1978) and expressed as the apparent dissociation constant $K_{\mathrm{A}}\left(-\log \mathrm{K}_{\mathrm{A}(\mathrm{app})}\right)$ (St-Louis et al. 2001). Sensitivity $\left(\mathrm{pD}_{2} ;\right.$ the negative logarithm of Angll concentration that produce $50 \%$ maximum response $\left(\mathrm{EC}_{50}\right)$ ) and $\mathrm{E}_{\text {Max }}$ were compared by one-way ANOVA, followed by Bonferroni comparison for selected pairs of groups with non-pregnant and pregnant animals on the control diet serving as controls. Values were considered to be statistically significant when they reached $P<0.05$. The data are reported as means \pm S.E.M. along with the curve best fitted to the data points.

\section{Drugs and chemicals}

All salts employed in these experiments were of analytical grade and obtained from Fisher Scientific (Montréal, QC, Canada). Angll (Asp ${ }^{1}, \|^{5}$-AngII) was purchased from Peninsula Laboratories (Belmont, CA, USA), phenylephrine hydrochloride and carbachol hydrochloride from Sigma Chemical Co. (St Louis, MO, USA) and L-NAME from Research Biochemical International (Natick, MA, USA). Losartan was generously provided by Merck Frosst (Montréal, QC, Canada).

\section{Results}

\section{Mechanical properties}

As reported previously (St-Louis et al. 1997), the uterine arcuate artery of the rat undergoes a large increase in size during pregnancy. In the present experiment, the diameter of vessel segments from the same anatomic location grew significantly from $122 \pm 4 \quad(n=24)$ to $270 \pm 12 \mu \mathrm{m}$ $(n=22)$ during pregnancy. The low-sodium diet did not affect arcuate artery diameter in non-pregnant animals $(140 \pm 10 \mu \mathrm{m}, n=10$; not significant (n.s.)), but markedly blunted the increase in the size of the vessels accompanying pregnancy $(198 \pm 15 \mu \mathrm{m}, n=10 ; P<0.05)$. Sodium supplementation did not change the diameter of the uterine arcuate artery of non-pregnant animals (122 $\pm 9 \mu \mathrm{m}$, $n=13$ and $111 \pm 5 \mu \mathrm{m}, n=12$ respectively for 0.9 and $1.8 \% \mathrm{NaCl}$ ). The diameter of the arterial segments in pregnant animals was reduced with sodium supplementation, although less markedly $(239 \pm 11 \mu \mathrm{m}, n=13$; n.s. and $230 \pm 12 \mu \mathrm{m}, n=17 ; P<0.05$ respectively for 0.9 and $1.8 \% \mathrm{NaCl}$, compared with normal pregnant controls) than with low-sodium diet.

Figure $1 \mathrm{~A}$ shows the length-tension relationship of the uterine arteries of non-pregnant and pregnant rats on the control and low-sodium diets. Pregnancy was associated with increased wall tension for any given relative stretch ( $\left.\mathrm{L} / \mathrm{L}_{50}\right)$ of arterial segment (the two solid lines). This can be explained by parameters of the exponential curves $\left(Y=A e^{\beta x}\right)$, in which $A$ is the wall tension at $L_{50}$ and $\beta$ represents the proportional changes in vessel circumference modifying wall tension. Pregnancy significantly heightened arterial wall tension at any given relative stretch (transmural pressure). This could be the consequence of the significant remodeling that affects the wall of uterine vessels during pregnancy (changes in diameter). On low-sodium intake, the increase in wall tension to relative stretch of the arcuate arteries was markedly increased (the two broken lines). Indeed, reduced sodium intake significantly augmented the exponential $\beta$ parameter (slope) of the equation (non-pregnant, from $3.36 \pm 0.43$ to $5.02 \pm 0.37$ and pregnant, from $3.02 \pm 0.20$ to $4.03 \pm 0.23$; both $P<0.05, n=10$ in all groups). Such an effect will produce steeper increments in wall tension with growing internal circumference of the arterial segment. This occurred in arteries of both non-pregnant and pregnant rats, although it was of significantly lower magnitude in the arteries of pregnant animals.

Figure 1B illustrates the length-tension relationship in the arcuate artery of non-pregnant and pregnant rats on control and high-sodium (two groups) intake. Sodium supplementation slightly modified the increased tension to relative stretch of these vessels, resulting in reductions of the $\beta$ parameter of the exponential relationship (non-pregnant, from $4.48 \pm 0.28(n=14)$ to $2.95 \pm 0.33(n=13)$ $(P<0.05)$ and $3.89 \pm 0.42(n=12)$ (n.s.) and pregnant, from $4.44 \pm 0.20 \quad(n=12) \quad$ to $3.09 \pm 0.17 \quad(n=13)$ $(P<0.05)$ and $3.91 \pm 0.15(n=17)$ (n.s.), for $0.9 \%$ and $1.8 \%$ supplementation respectively). This demonstrated that, opposite to the low-sodium diet, the arteries of rats on sodium supplements showed decreased tension responses to relative changes in circumferential stretch (smaller exponential slope) compared with normally fed rats. 


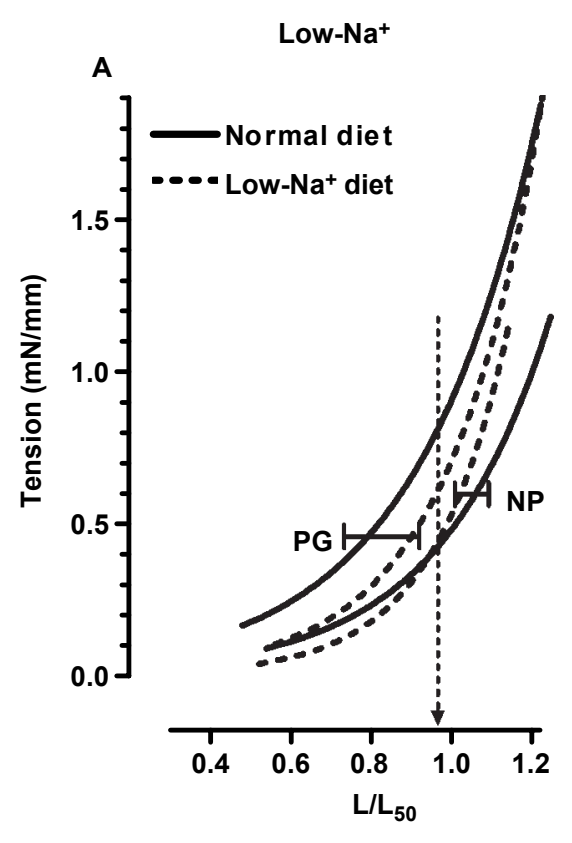

\section{Responses to Angll}

Figure 2A depicts the myotropic responses to Angll in uterine arcuate arteries of non-pregnant and pregnant rats on the control diet, in the absence and presence of the $\mathrm{AT}_{1}$ receptor antagonist losartan $(100 \mathrm{nmol} / \mathrm{l})$. In the vessels of pregnant compared with non-pregnant animals, the effects of Angll were markedly increased (Table 1; $\mathrm{E}_{\text {Max, }}$ control groups). Sensitivity of the arcuate artery to Angll $\left(\mathrm{pD}_{2}\right)$ was not significantly changed by gestation.

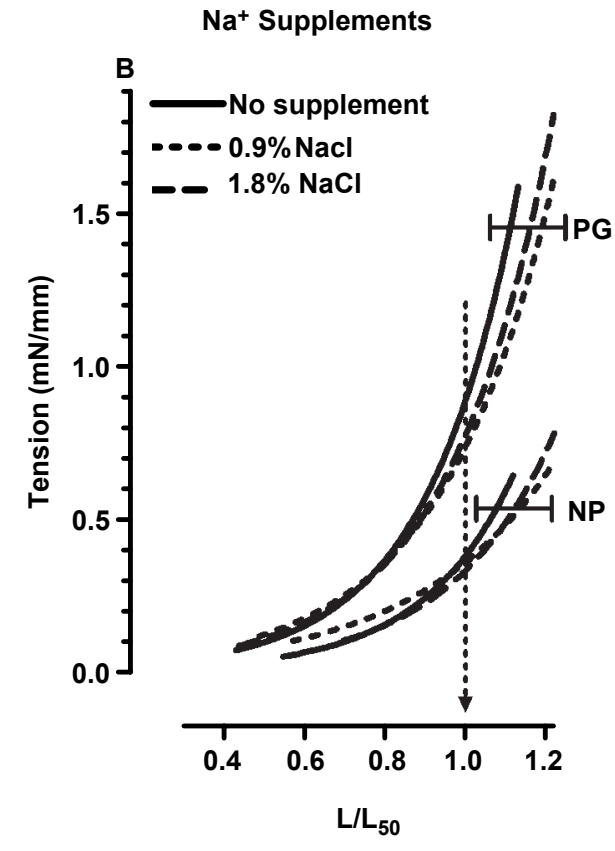

Figure 1 Length-tension relationship in the uterine arcuate arteries of non-pregnant (NP) and pregnant (PG) rats on (A) regular and low-sodium diets and (B) regular and high-sodium intake. The vertical broken line at unit abscissa is indicative of the A parameter in the exponential equation to which the curves were fitted (see Materials and Methods). The intersection of the solid line with the relative broken lines is indicative of the $\beta$ parameter of the same equation. The ordinate describes the tension responses (in $\mathrm{mN} / \mathrm{mm}$ ) to step increases of relative internal circumference of the vessel $\left(\mathrm{L} / \mathrm{L}_{50}\right)$.
In both conditions, concentration-response curves to Angll were markedly right-shifted in the presence of $100 \mathrm{nmol} / \mathrm{l}$ losartan (broken lines in Fig. 2A), significantly more in non-pregnant than in pregnant rats. Indeed, fitting these curves to the sigmoid equation was compatible with competitive antagonism for losartan, since the same maximum responses could be fitted in both the presence and absence of the antagonist with a slope not different from unity. This allowed the calculation of an apparent
Control diet

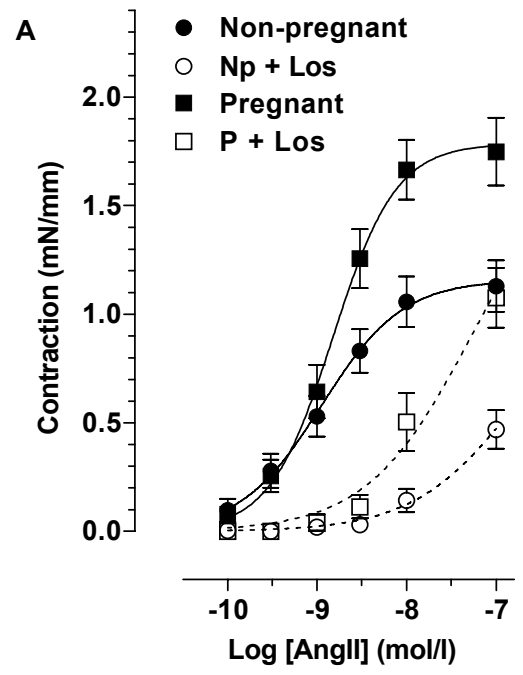

Low-Na+ diet

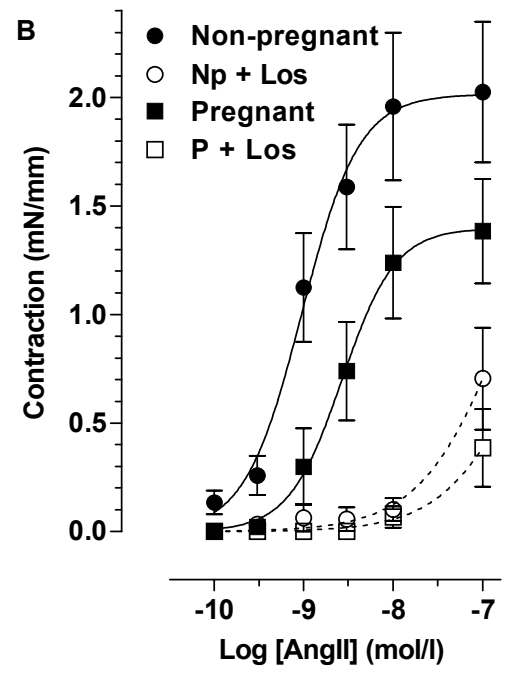

Pregnant

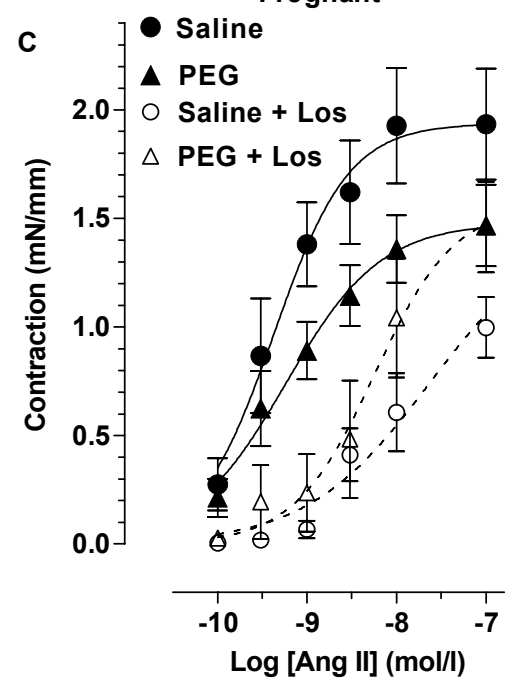

Figure 2 Contractile responses to Angll in uterine arcuate arteries of non-pregnant $(\mathrm{Np})$ and pregnant $(\mathrm{P})$ rats in the absence and presence of $100 \mathrm{nmol} / / \mathrm{l}$ losartan (Los). Data were obtained in rats on (A) normal or (B) low-sodium intakes and (C) after treatment of pregnant rats with PEG or saline. Each point is the mean of 7-24 experiments, while the line represents the best fit of all the individual experimental points. 
Table 1 Effects of the different conditions tested on reactivity to Phe and Angll $\left(\mathrm{E}_{\max }\right.$ and $\left.\mathrm{pD}_{2}\right)$ and on apparent sensitivity ( $\left.-\log K_{\mathrm{A}(\mathrm{app})}\right)$ to losartan, an $\mathrm{AT}_{1}$ antagonist. Values are means \pm S.E.M.

\begin{tabular}{|c|c|c|c|c|c|}
\hline & No. & Phe $(\mathrm{mN} / \mathrm{mm})$ & $\mathbf{E}_{\text {Max }}(\mathrm{mN} / \mathrm{mm})$ & $\mathrm{pD}_{2}$ & $-\log K_{\mathrm{A}(\mathrm{app})}$ \\
\hline \multicolumn{6}{|l|}{ Non-pregnant } \\
\hline Control & 24 & $0.66 \pm 0.08$ & $1.16 \pm 0.10$ & $8.98 \pm 0.11$ & $9.21 \pm 0.09$ \\
\hline Low $\mathrm{Na}^{+}$ & 10 & $1.04 \pm 0.20 *$ & $2.01 \pm 0.20 *$ & $9.04 \pm 0.11$ & $9.39 \pm 0.11$ \\
\hline $0.9 \% \mathrm{NaCl}$ & 13 & $0.32 \pm 0.06 *$ & $1.18 \pm 0.13$ & $9.03 \pm 0.14$ & $8.58 \pm 0.22 *$ \\
\hline $1.8 \% \mathrm{NaCl}$ & 12 & $0.59 \pm 0.10$ & $0.96 \pm 0.10$ & $8.78 \pm 0.11$ & $9.09 \pm 0.14$ \\
\hline \multicolumn{6}{|l|}{ Pregnant } \\
\hline Control & 22 & $1.13 \pm 0.10+$ & $1.79 \pm 0.11 \dagger$ & $8.91 \pm 0.07$ & $8.54 \pm 0.15+$ \\
\hline Low $\mathrm{Na}^{+}$ & 10 & $0.83 \pm 0.23$ & $1.40 \pm 0.17 *+$ & $8.54 \pm 0.09 * \dagger$ & $8.96 \pm 0.11 *+$ \\
\hline $0.9 \% \mathrm{NaCl}$ & 13 & $1.05 \pm 0.12+$ & $1.42 \pm 0.10 *$ & $9.11 \pm 0.06$ & $9.25 \pm 0.29 *+$ \\
\hline $1.8 \% \mathrm{NaCl}$ & 17 & $0.89 \pm 0.10 \dagger$ & $1.56 \pm 0.15 t$ & $8.92 \pm 0.07$ & $8.20 \pm 0.12 \dagger$ \\
\hline Saline (PEG) & 7 & $1.43 \pm 0.22$ & $1.94 \pm 0.18$ & $9.34 \pm 0.07 \ddagger$ & $8.34 \pm 0.24$ \\
\hline PEG & 9 & $0.85 \pm 0.12 \neq$ & $1.48 \pm 0.15 \neq$ & $9.27 \pm 0.10$ & $8.67 \pm 0.15$ \\
\hline
\end{tabular}

Phe, the response to $1.0 \mu \mathrm{mol} / \mathrm{l}$ of this agonist given at the beginning of the experiment.

$\mathrm{E}_{\mathrm{Max}}$ is the mean of maximum asymptote of the fitted response to individual data points.

* Compared with the control group under the same condition, pregnant or not.

tCompared with the corresponding group of non-pregnant rats.

₹ Saline compared with the pregnant control group, while the PEG group is compared with saline.

dissociation constant $\left(-\log K_{\mathrm{A}(\mathrm{app})}\right)$ for losartan (Furchgott 1978). Such a calculation indicated that sensitivity to losartan was significantly decreased in arteries of pregnant compared with non-pregnant rats (Table 1). The initial response to Phe $(1.0 \mu \mathrm{mol} / \mathrm{l})$ was increased in arteries of pregnant rats, as was the Angll maximum response.

The data on reactivity to Angll in the arcuate arteries of rats on low-sodium intake are reported in Fig. 2B. Opposite results were obtained, since the arteries of non-pregnant animals presented stronger responses to Angll than those of pregnant rats ( $E_{\text {Max; }}$ Table 1). Angll responses of the arteries of non-pregnant rats on the lowsodium diet were not different from pregnant rats on the control diet, whereas the arteries of pregnant rats on the low-sodium diet showed similar responses to Angll as non-pregnant rats on the control diet (Fig. 2A and B). Sensitivity to Angll was decreased in the arcuate arteries of pregnant animals under low sodium (Table 1), as illustrated by the rightward shift of the concentrationresponse curve in Fig. 2B. Again, losartan produced strong inhibition of Angll responses and the apparent affinity of the $\mathrm{AT}_{1}$ receptor antagonist was reduced in the arcuate arteries of pregnant compared with non-pregnant rats. The response to Phe was increased in the arteries of non-pregnant rats on the low-sodium diet, but no change was observed in the pregnant animals (Table 1).

As the low-sodium diet during the third (last) week of gestation elicited a marked reduction of blood volume expansion (Roy-Clavel et al. 1999), we attempted some plasma volume reduction with subcutaneous injections of PEG, compared with saline, during the same period of pregnancy. As expected, this manoeuvre evoked a pronounced increase of the RAAS, as demonstrated by elevation of PRA from $8.8 \pm 1.1$ to $28 \pm 5 \mathrm{pmol} A \mathrm{ngl} / \mathrm{ml}$ per $\mathrm{h}$, and aldosterone from $1.3 \pm 0.3$ to $16 \pm 3 \mathrm{nmol} / \mathrm{ml}$ $(n=7$ and 9 respectively). Hematocrit was also augmented (from $33 \pm 1.3$ to $35 \pm 1 \% ; P<0.05$ ) upon PEG treatment, indicating significant hemoconcentration, while plasma sodium fell from $136 \pm 1$ to $124 \pm 2 \mathrm{mmol} / \mathrm{l}$. These data resemble those obtained with the low-sodium diet (Roy-Clavel et al. 1999).

The uterine arcuate arteries of PEG- and saline-treated rats had a similar diameter $(270 \pm 16 \quad(n=7)$ vs $290 \pm 16 \mu \mathrm{m} \quad(n=9))$. Similarly, the length-tension relationship in uterine arcuate arteries was not affected by PEG (data not shown). Figure 2C reveals that PEG significantly reduced the maximum response to Angll, similarly to low-sodium intake. Sensitivity to Angll and losartan was not affected by PEG in pregnant rats, results that were somewhat different from findings in pregnant rats on normal and low-sodium intakes. The contractile effect of Phe $(1.0 \mu \mathrm{mol} / \mathrm{l})$ was reduced to a similar level as in rats on the low-sodium diet by PEG treatment (Table 1).

Reactivity to Angll, measured in the arteries of rats given sodium supplements as 0.9 or $1.8 \%$ saline for beverage, is shown in Fig. 3. Compared with the control diet (Fig. 2A), the two sodium supplements did not modify the maximum response of the uterine arcuate arteries to Angll in non-pregnant rats (Table 1). In pregnant rats, the increased response to Angll was blunted by sodium supplements, although this was significant only in the $0.9 \%$ saline group (Table 1). Sensitivity to Angll was not different in the four groups of animals (non-pregnant and pregnant on both supplements) from those on normal sodium intake. The apparent potency of inhibition of the Angll response by losartan was decreased in the arteries of nonpregnant rats on $0.9 \% \mathrm{NaCl}$ supplementation and also in tissues of pregnant rats. $1.8 \% \mathrm{NaCl}$ supplemention did not affect apparent sensitivity to losartan in both groups of animals (Table 1). The response of the uterine arcuate arteries to Phe was significantly modified (decreased) only in the arteries of non-pregnant rats on $0.9 \% \mathrm{NaCl}$ (Table 1 ). 


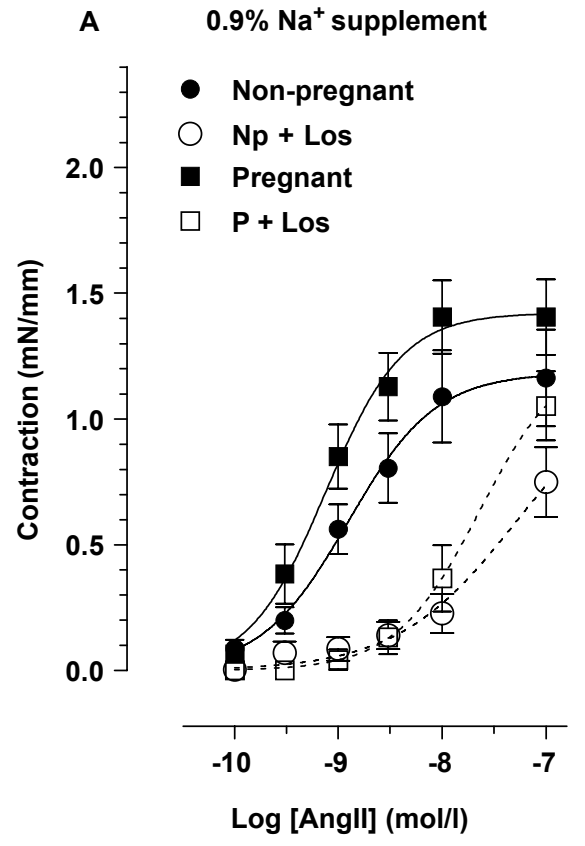

\section{Discussion}

The present experiments were undertaken to determine the influence of modifications of the RAAS during pregnancy on size and on the mechanical and pharmacological properties of the uterine arcuate artery. These modifications were induced by decreasing and increasing the sodium content of the diet. Our results globally showed that low- and high-sodium intakes for a short period of time (7 days) have a much stronger impact during pregnancy than in non-pregnant animals. Of all potential causes of chronic hypertension, dietary sodium and the RAAS have been recurrent themes of investigation. However, it is well known that pregnancy is accompanied by paradoxical responses of the RAAS, since, in the rat, an increase in PRA precedes the decrease in blood pressure (Conrad et al. 1989). A recent clinical study demonstrated that both PRA and aldosterone levels progressively increase during normotensive pregnancy, these values always being higher than in hypertensive pregnant women (Elsheikh et al. 2001). We have reported similar observations for PRA and elevated plasma aldosterone at the end of gestation in the rat (Roy-Clavel et al. 1999). It was also observed that a low-sodium diet, given during the last week of gestation, was associated with RAAS overactivation, since increased PRA and aldosterone were further markedly augmented. This was accompanied by reduced plasma volume expansion while the fall in blood pressure still occurred, again an intriguing paradoxical finding. On the other hand, increased sodium intake, given as saline beverage (0.9 or $1.8 \% \mathrm{NaCl})$, evoked marked RAAS suppression (both PRA and aldosterone) and resulted in absence of the normally associated
$1.8 \% \mathrm{Na}^{+}$supplement

$\begin{array}{ll}\text { - } & \text { Non-pregnant } \\ \bigcirc & \text { Np + Los } \\ \square & \text { Pregnant } \\ \square & \text { P + Los }\end{array}$

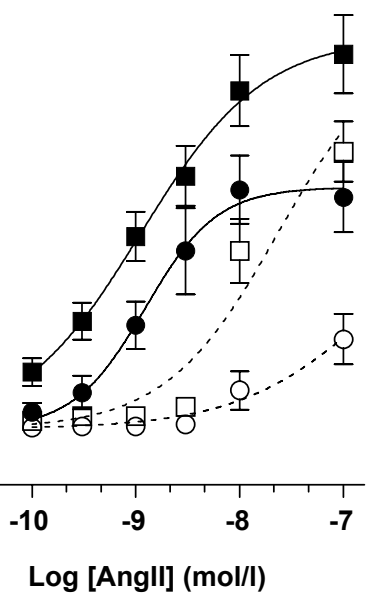

Figure 3 Contractile responses to Angll in uterine arcuate arteries of non-pregnant $(\mathrm{Np})$ and pregnant $(\mathrm{P})$ rats on (A) $0.9 \%$ and (B) $1.8 \%$ saline supplements in the absence and presence of $100 \mathrm{nmol} / \mathrm{l}$ losartan (Los). Each point is the mean of 12-17 experiments, while the line represents the best fit of all the individual experimental points.

blood pressure decline at the end of gestation (Beauséjour et al. 2003).

During pregnancy, the uterine circulation has to adapt to the growing nutritional needs of the fetus(es). In fact, blood flow to the reproductive organs is enhanced by 23 -fold during gestation in the rat through more than $75 \%$ increased diameter of the parametrial (main) and segmental (arcuate) arteries (Bruce 1976). This fits with our present and previous (St-Louis et al. 1997, 2001) observations as well as reports in the literature (Annibale et al. 1990, D'Angelo \& Osol 1993, Osol \& Cipolla 1993a, Cipolla \& Osol 1994, Dalle-Lucca et al. 2000). Modified sodium intake did not have any effect on uterine artery size in non-pregnant rats, but blunted the increase in diameter of these arteries during gestation. As observed previously, we recorded heightened passive tension to stretch of the uterine arcuate arteries of pregnant compared with non-pregnant rats (St-Louis et al. 1997, 2001), similar to the results presented in Fig. 1. Such findings were also made in pregnant sheep uterine arteries (Annibale et al. 1990). However, the current data suggest that this is probably the consequence of the arterial wall remodeling associated with pregnancy (Cipolla \& Osol 1994). Indeed, pregnancy did not much affect the exponential increase in tension upon stretching, but markedly augmented resting wall tension at normalized distension (Mulvany \& Halpern 1977), an augmentation that is compatible with enlarged lumen diameter, without change in wall thickness (Annibale et al. 1990, Osol \& Cipolla 1993a, D'Angelo \& Osol 1994, St-Louis et al. 1997). On the other hand, the low-sodium diet enhanced the exponential increase in tension upon circumferential stretching of the arterial segment, whereas 
$0.9 \%$ sodium supplementation decreased this parameter. These effects were of a similar magnitude in the arteries of non-pregnant and pregnant rats. This appears to be an original observation. Nevertheless, our findings reveal that decreased and increased sodium intakes have opposite effects on the mechanical properties of uterine arcuate arteries. The impact of these opposite effects of decreased and increased sodium intake on uterine blood flow during pregnancy remains to be investigated, but reported observations suggest that the enhanced stiffness and/or reduced diameter of the uterine arcuate artery on a low-sodium diet (present study) are associated with intrauterine growth restriction of the pups (Roy-Clavel et al. 1999).

It is well recognized that gestation is associated with increased reactivity of the uterine arterial system to vasoconstrictors (Annibale et al. 1989, D'Angelo \& Osol 1993, St-Louis et al. 1997, Zwart et al. 1998, Dalle-Lucca et al. 2000). Treatment with the low-sodium diet and sodium supplements also had significant effects on the reactivity of the uterine artery to Angll that are not similar in pregnant and non-pregnant rats. In the latter, the low-sodium diet markedly increased uterine vascular responses to the peptide, whereas sodium supplementation $(1.8 \%)$ was associated with a slight decrease of maximum responses to Angll. In pregnant animals, the enhanced contractile effect of the peptide on the uterine arcuate artery was completely obliterated (or reversed) by the low-sodium diet. Similar results were obtained with the initial response to Phe $(1.0 \mu \mathrm{mol} / \mathrm{l})$. Sodium supplementation also induced similar decreases in the responses to Angll in uterine arteries compared with normally fed pregnant rats. It is suggested that sodium homeostasis is easily disturbed during pregnancy, while non-pregnant animal are hardly affected.

Similar modifications of salt intake resulted in very different responses of the rat aorta. Indeed, reduction of sodium intake (chow containing $0.2 \%$ instead of $1 \%$ $\mathrm{NaCl}$ ) increased the reactivity of thoracic aorta strips to Phe and $\mathrm{KCl}$ that was only significant in pregnant rats and in a model of reduced uterine perfusion pressure (RUPP) during gestation (Giardina et al. 2002). Their results in non-pregnant rats fit with the large increase in the maximum response to Angll that we obtained in uterine arteries whereas, in pregnant animals, it appears that the decrease under low-sodium is specific for either uterine arteries or Angll responses. Specificity to the uterine vasculature seems to be appropriate since the initial responses to Phe $(1.0 \mu \mathrm{mol} / \mathrm{l})$ were similarly affected by low-sodium intake (Table 1).

In similar experiments with increased sodium intake $(8 \%$ vs $1 \% \mathrm{NaCl})$, heightened responses to Phe in the aorta of pregnant rats, both normal and RUPP, were observed (Barron et al. 2001). In our sodium-supplemented groups, the aortic rings of non-pregnant rats manifested decreased maximal responses to Phe and arginine-vasopressin, but not to $\mathrm{KCl}$. However, the reduced maximal responses to these agents observed in the aorta of pregnant compared with non-pregnant rats were reversed by sodium supplementation (Auger et al. 2004). In the present results, reduced responses to Angll in uterine arcuate arteries were obtained with both sodium supplements in pregnant rats and with $1.8 \% \mathrm{NaCl}$ in nonpregnant animals. This closely resembles our data in the aorta (Auger et al. 2004) more than the findings of Barron et al. (2001).

Concerning sensitivity to Angll, our results were complicated by the presence of $\mathrm{AT}_{2}$ receptor subtypes in these blood vessels (Zwart et al. 1998, St-Louis et al. 2001, Hannan et al. 2003). Indeed, it has been shown that blockade of $\mathrm{AT}_{2}$ with PD 123319, its specific ligand, potentiated the contractile effects of Angll on uterine arteries (Zwart et al. 1998, St-Louis et al. 2001). This increased response to Angll was attributed to some unidentified inhibitory action of $\mathrm{AT}_{2}$ stimulation on the responses mediated by $\mathrm{AT}_{1}$ stimulation. Sensitivity of the arcuate artery to Angll was not significantly modified by different sodium intakes compared with the control diet in non-pregnant animals. This also holds true for pregnant animals, except on the low-sodium diet when significantly decreased sensitivity to Angll was observed. The heightened response to Angll was attributed to uncoupling of $\mathrm{AT}_{2}$ inhibition, consequent to the reduced density of this receptor subtype (Zwart et al. 1998, St-Louis et al. 2001). As reported previously, sensitivity of the uterine arcuate artery to losartan was significantly diminished by pregnancy despite the large increase of the maximum response (St-Louis et al. 2001). The lowsodium diet in pregnant rats significantly enhanced the sensitivity of the arcuate arteries to losartan, but not in non-pregnant animals.

While the low-sodium diet had similar effects on sensitivity of the uterine arteries to losartan in both groups of rats, sodium supplementation provided more complex results. The $0.9 \%$ sodium supplement significantly decreased sensitivity to losartan in the arteries of nonpregnant animals and increased it in pregnant rats. In contrast, the $1.8 \%$ supplement did not show any significant effects on this parameter compared with rats in the same condition on the control diet. This suggests that the $1.8 \%$ sodium supplement restored sensitivity to losartan to the level obtained with the regular diet, but more work is needed to explain such discrepancies.

In conclusion, modifications of sodium intake have significant effects on the mechanical properties of uterine arcuate arteries that are similar in magnitude in pregnant and non-pregnant rats, but which go in opposite directions with reduced and increased sodium intakes. This indicates that perturbations of sodium balance or of the RAAS during pregnancy interfere with the uterine vascular remodeling associated with the condition. In contrast, altered sodium intake has significant effects on the reactivity of these arteries to Angll that are very different in pregnant and non-pregnant rats. The 
involvement of $\mathrm{AT}_{1}$ receptors in these changes appears to vary according to pregnancy and sodium intake, suggesting, as postulated (St-Louis et al. 2001), the regulation of Angll receptor subtypes that so far has remained undocumented. The results presented here are indicative of a modified influence or role of the RAAS during gestation. For instance, during low sodium diet and PEG treatment in pregnant animals, increased RAAS, probably as a result of reduced plasma volume (hematocrit elevation), impedes remodeling of the uterine arterial system, modifying the size and reactivity of the uterine arcuate artery. In the increased sodium intake model, only the reduction of plasma volume, probably caused by the need to excrete more water and sodium, contributes to the smaller attenuation of remodeling with much less impact on size and reactivity of the uterine arcuate artery. However, the present data clearly demontrate that sodium handling is more critical during pregnancy.

\section{Acknowledgements}

This work was supported by a grant from the Canadian Institute for Health Research, \#MOP 62790 to JSL. The authors declare that there is no conflict of interest that would prejudice the impartiality of this scientific work.

\section{References}

Annibale DJ, Rosenfeld CR \& Kamm KE 1989 Alterations in vascular smooth muscle contractility during ovine pregnancy. American Journal of Physiology. Heart and Circulation Physiology 256 $\mathrm{H} 1282-\mathrm{H} 1288$.

Annibale DJ, Rosenfeld CR, Stull JT \& Kamm KE 1990 Protein content and myosin light chain phosphorylation in uterine arteries during pregnancy. American Journal of Physiology. Cell Physiology 259 C484-C489.

Auger K, Beauséjour A, Brochu M \& St-Louis J 1856 Increased $\mathrm{Na}^{+}$ intake during gestation in rats is associated with enhanced vascular reactivity and alterations of $\mathrm{K}^{+}$and $\mathrm{Ca}^{++}$function. American Journal of Physiology. Heart and Circulation Physiology 287 $\mathrm{H} 1848-\mathrm{H} 1856$.

Barron LA, Giardina JB, Granger JP \& Khalil RA 2001 High-salt diet enhances vascular reactivity in pregnant rats with normal and reduced uterine perfusion pressure. Hypertension 38 730-735.

Baylis C, Beinder E, Suto T \& August P 1998 Recent insights into the roles of nitric oxide and renin-angiotensin in the pathophysiology of preeclamptic pregnancy. Seminars in Nephrology $\mathbf{1 8}$ 208-230.

Beauséjour A, Auger K, St-Louis J \& Brochu M 2003 High-sodium intake prevents pregnancy-induced decrease of blood pressure in the rat. American Journal of Physiology. Heart and Circulation Physiology $285 \mathrm{H} 375-\mathrm{H} 383$.

Bird IM, Zheng J, Cale JM \& Magness RR 1997 Pregnancy induces an increase in angiotensin II type-1 receptor expression in uterine but not systemic artery endothelium. Endocrinology 138 490-498.

Bruce NW 1976 The distribution of blood flow to the reproductive organs of rats near term. Journal of Reproduction and Fertility $\mathbf{4 6}$ 359-362.

Burrell JH \& Lumbers ER 1997 Angiotensin receptor subtypes in the uterine artery during ovine pregnancy. European Journal of Pharmacology $330257-267$.
Cipolla M \& Osol G 1994 Hypertrophic and hyperplastic effects of pregnancy on the rat uterine arterial wall. American Journal of Obstetrics and Gynecology 171 805-811.

Cipolla M, Binder ND \& Osol G 2000 Myoendometrial versus placental uterine arteries: structural, mechanical, and functional differences in late pregnant rabbits. American Journal of Obstetrics and Gynecology 177 215-221.

Conrad KP, Morganelli PM, Brinck-Johnsen T \& Colpoys MC 1989 The renin-angiotensin system during pregnancy in chronically intrumented, concious rats. American Journal of Obstetrics and Gynecology 161 1065-1072.

Cox BE, Rosenfeld CR, Kalinyak JE \& Magness RR 1996a Tissue specific expression of vascular smooth muscle angiotensin II receptor subtypes during ovine pregnancy. American Journal of Physiology. Heart and Circulation Physiology $271 \mathrm{H} 212-\mathrm{H} 221$.

Cox BE, Word RA \& Rosenfeld CR 1996b Angiotensin II receptor characteristics and subtype expression in uterine arteries and myometrium during pregnancy. Journal of Clinical Endocrinology and Metabolism 81 49-58.

Dalle-Lucca JJ, Adeagbo ASO \& Alsip NL 2000 Oestrus cycle and pregnancy alter the reactivity of the rat uterine vasculature. Human Reproduction 15 2496-2503.

D'Angelo G \& Osol G 1993 Regional variation in resistance artery diameter responses to $\alpha$-adrenergic stimulation during pregnancy. American Journal of Physiology $264 \mathrm{H} 78-\mathrm{H} 85$.

D'Angelo G \& Osol G 1994 Modulation of uterine resistance artery lumen diameter by calcium and $\mathrm{G}$ protein activation during pregnancy. American Journal of Physiology 267 H952-H961.

Elsheikh A, Creatsas G, Mastorakos G, Milingos S, Loutradis D \& Michalas S 2001 The renin-aldosterone system during normal and hypertensive pregnancy. Archives of Gynaecology and Obstetrics $264182-185$.

Furchgott RF 1978 Pharmacological characterization of receptors: its relation to radioligand-binding studies. Federation Proceedings $\mathbf{3 7}$ 115-120.

Giardina JB, Cockrell KL, Granger JP \& Khalil RA 2002 Low-salt diet enhances vascular reactivity and $\mathrm{Ca}^{2+}$ entry in pregnant rats with normal and reduced uterine perfusion pressure. Hypertension 39 $368-374$.

Hannan RE, Davis EA \& Widdop RE 2003 Functional role of angiotensin $\mathrm{II} \mathrm{AT}_{2}$ receptor in modulation of $\mathrm{AT}_{1}$ receptor-mediated contraction in rat uterine artery: involvement of bradykinin and nitric oxide. British Journal of Pharmacology 140 987-995.

Mulvany MJ \& Halpern W 1977 Contractile properties of small arterial resistance vessels in spontaneously hypertensive and normotensive rats. Circulation Research 41 19-26.

Ni Y, Meyer M \& Osol G 1997 Gestation increases nitric oxide-mediated vasodilation in rat uterine arteries. American Journal of Obstetrics and Gynecology 176 856-864.

Osol G \& Cipolla MP 1993a Pregnancy-induced changes in the three-dimensional mechanical properties of pressurized rat uteroplacental (radial) arteries. American Journal of Obstetrics and Gynecology 168 268-274.

Osol G \& Cipolla M 1993b Interaction of myogenic and adrenergic mechanisms in isolated, pressurized uterine radial arteries from late-pregnant and nonpregnant rats. American Journal of Obstetrics and Gynecology 168 697-705.

Rosenfeld CR 2001 Mechanisms regulating angiotensin II responsiveness by uteroplacental circulation. American Journal of Physiology. Regulatory, Integrative and Comparative Physiology $\mathbf{2 8 1}$ R1025-R1040.

Roy-Clavel E, Picard S, St-Louis J \& Brochu M 1999 Induction of uterine growth restriction with low-sodium diet fed to pregnant rats. American Journal of Obstetrics and Gynecology $\mathbf{1 8 0}$ $608-613$.

St-Louis J \& Schiffrin EL 1984 Biological action and binding sites for vasopressin on mesenteric artery from normal and sodiumdepleted rats. Life Sciences 35 1489-1495. 
St-Louis J, Paré H, Sicotte B \& Brochu M 1997 Increased reactivity of uterine arcuate artery throughout pregnancy and postpartum. American Journal of Physiology $273 \mathrm{H} 1148-\mathrm{H} 1153$.

St-Louis J, Sicotte B, Bédard S \& Brochu M 2001 Blockade of angiotensin receptor subtypes in arcuate uterine artery of pregnant and post-partum rats. Hypertension 38 1017-1023.

Simon G \& Illyes G 2001 Structural vascular changes in hypertension: role of angiotensin II, dietary sodium supplementation, and sympathetic stimulation, alone or in combination in rats. Hypertension 37 255-260.
Zwart AS, Davis EA \& Widdop RE 1998 Modulation of $\mathrm{AT}_{1}$ receptor-mediated contraction of rat uterine artery by $\mathrm{AT}_{2}$ receptors. British Journal of Pharmacology 125 1429-1436.

Received 3 February 2005

First decision 10 October 2005

Revised manuscript received 26 October 2005

Accepted 1 November 2005 